Supporting Information

\title{
Efficient Anticancer Drug Delivery for Pancreatic Cancer Treatment Utilizing Supramolecular Polyethylene-Glycosylated Bromelain
}

Taishi Higashi ${ }^{\dagger, \star * \#, *,}$, Tetsuya Kogo ${ }^{\star * \#}$, Nana Sato ${ }^{\ddagger} \#$, Tatsunori Hirotsu ${ }^{\star}$, Shogo Misumi ${ }^{\star}$, Hideaki Nakamura ${ }^{\S}$, Daisuke Iohara ${ }^{\S}$, Risako Onodera ${ }^{\ddagger}$, Keiichi Motoyama ${ }^{\ddagger}$, Hidetoshi Arima $\|$, *

${ }^{\dagger}$ Priority Organization for Innovation and Excellence, Kumamoto University, 5-1 Oe-honmachi, Chuo-ku, Kumamoto 862-0973, Japan

* Graduate School of Pharmaceutical Sciences, Kumamoto University, 5-1 Oe-honmachi, Chuo-ku, Kumamoto 862-0973, Japan

§ Program for Leading Graduate Schools "HIGO (Health life science: Interdisciplinary and Glocal Oriented) Program”, Kumamoto University, 5-1 Oe-honmachi, Chuo-ku, Kumamoto 862-0973, Japan

${ }^{\S}$ Faculty of Pharmaceutical Sciences, Sojo University, 4-22-1 Ikeda, Nishi-ku, Kumamoto 860-0082, Japan

"Laboratory of Evidence-Based Pharmacotherapy, Daiichi University of Pharmacy, 22-1 Tamagawamachi, Minami-ku, Fukuoka 815-8511 Japan

\# These authors contributed equally to this work.

* Corresponding author.

Taishi Higashi, Hidetoshi Arima

E-mail: higashit@kumamoto-u.ac.jp (T. H.), h-arima@ daiichi-cps.ac.jp (H. A.) TEL: +8196371 4168, FAX: +81963714420 


\section{PEG- $\beta$-CyD (2)}

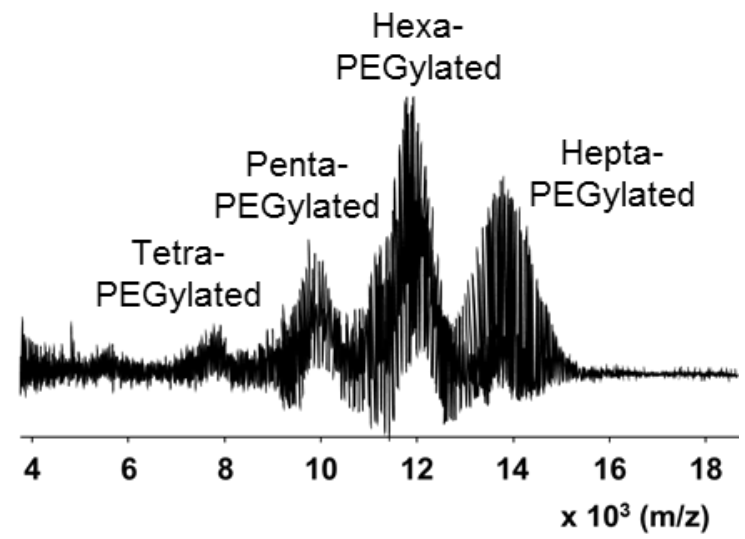

Figure S1. MALDI-TOF MS spectrum of PEG- $\beta$-CyD (2).

\section{PEG- $\beta$-CyD (20)}

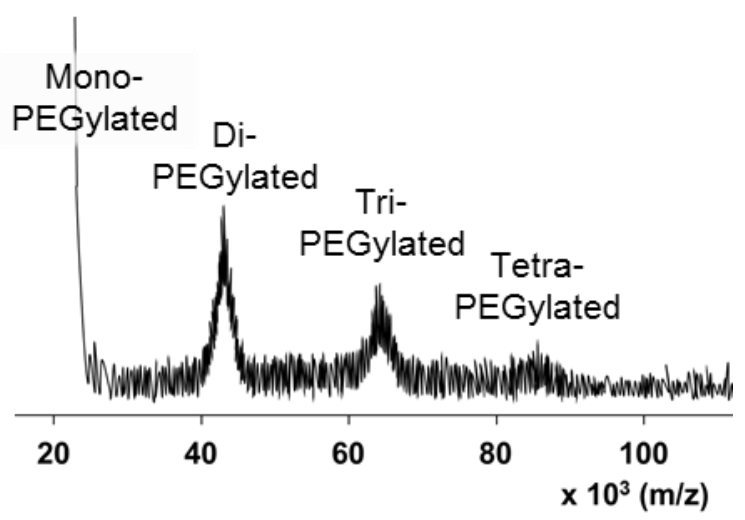

Figure S2. MALDI-TOF MS spectrum of PEG- $\beta$-CyD (20). 


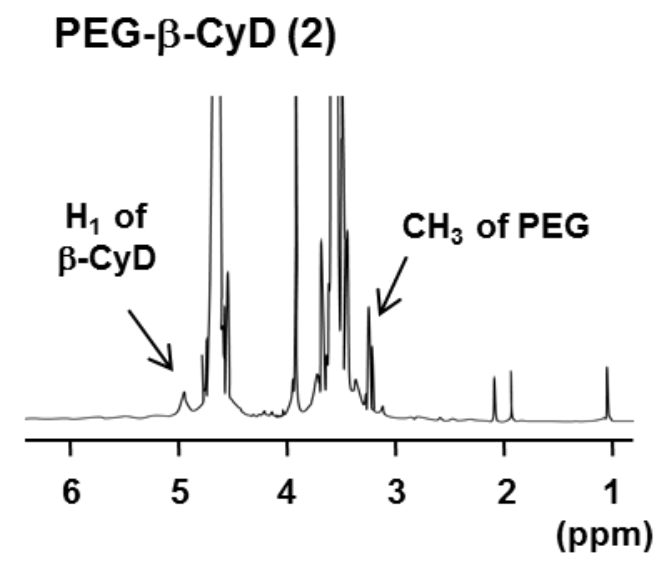

Figure S3. ${ }^{1} \mathrm{H}-\mathrm{NMR}$ spectrum of PEG- $\beta$-CyD (2).

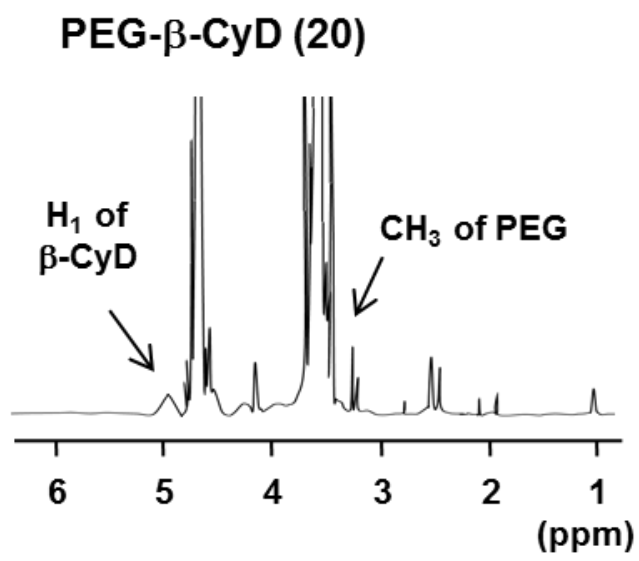

Figure S4. ${ }^{1} \mathrm{H}-\mathrm{NMR}$ spectrum of PEG- $\beta$-CyD (20).

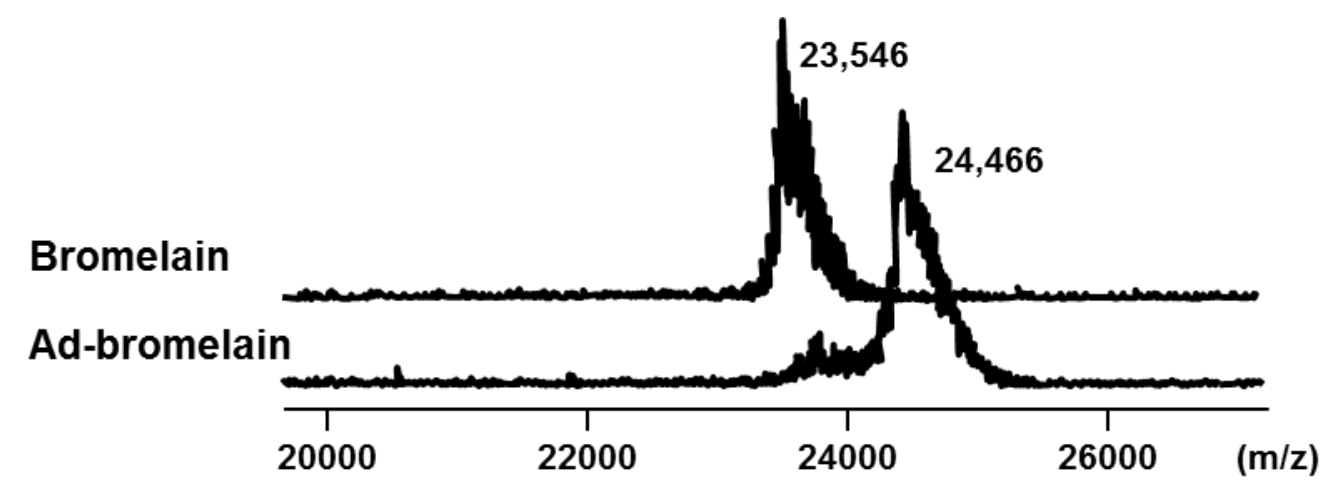

Figure S5. MALDI-TOF MS spectra of bromelain and Ad-bromelain. 

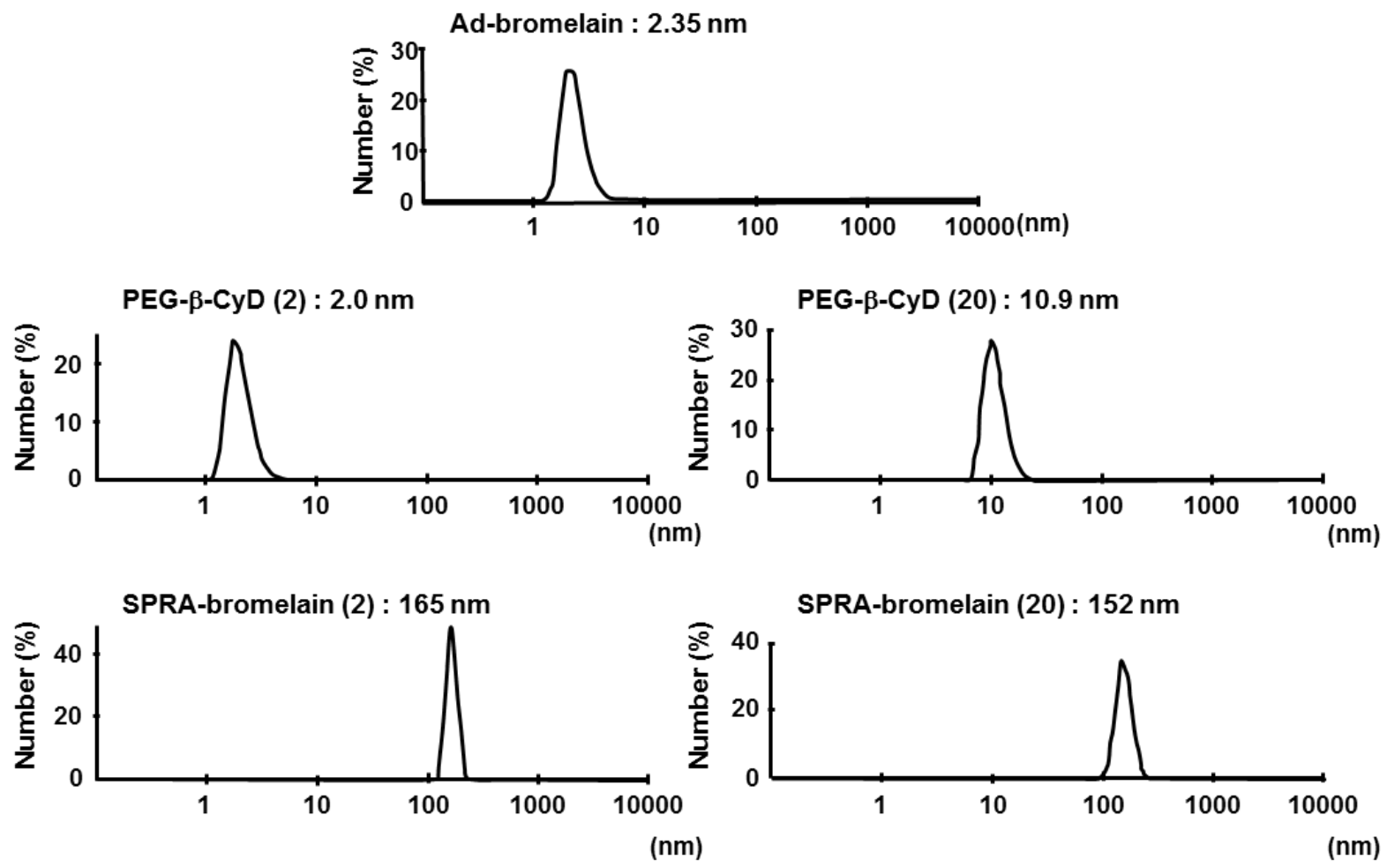

Figure S6. Particle sizes of Ad-bromelain, PEG- $\beta$-CyDs, and SPRA-bromelains. The particle sizes were measured by a Zetasizer Nano. The samples were dissolved in 5\% mannitol solution (pH 7.4). The concentration of bromelain was $1 \mathrm{mg} / \mathrm{mL}$. The molar ratio of PEG- $\beta$-CyDs/Ad-bromelain was 10/1. 